* Advogado. Especialista em Direito Empresarial (FGV). Mestrando em Direito Ambiental e Sustentabilidade pela Escola Superior Dom Helder Câmara (ESDHC).

E-mail: marcos@lawyer.com

** Doutor e Mestre em Direito. Professor do Programa de Pósgraduação em Direito da Escola Superior Dom Helder Câmara (ESDHC).

E-mail: elcionrezende@yahoo. com.br

\section{Responsabilidade Civil Ambiental Decorrente do Serviço Público de Fornecimento de Energia ELÉTRICA}

\author{
Environmental Civil Liability Arising From The \\ Public Service Of The Electrical Energy Supply
}

\section{Marcos Vinicius Rodrigues* Elcio Nacur Rezende**}

Como citar: RODRIGUES, Marcos Vinicius; REZENDE, Elcio Nacur. Responsabilidade civil ambiental decorrente do serviço público de fornecimento de energia elétrica. Revista do Direito Público, Londrina, v. 14, n. 3, p. 49-63, dez. 2019. DOI: 10.5433/24157-108104-1.2019v14n3p. 49. ISSN: 1980-511X

Resumo: O presente artigo analisou a responsabilidade civil e ambiental das empresas prestadoras de serviço público, em especial, as concessionárias de energia elétrica, utilizandose da metodologia fundada na análise doutrinária, normativa e jurisprudencial, promovendo-se um raciocínio crítico-dedutivo. Nesse sentido, à luz da necessidade de energia como um direito fundamental, nos debruçamos sobre os desafios de se efetivar a proteção do meio ambiente e as imbricações no concernente à responsabilização por danos ambientais provocados pela prestação do fornecimento de energia.

Palavras-chave: Serviço público. Energia hidrelétrica. Responsabilidade civil.

Abstract: This study explores civil and environmental liability of public service companies, particularly, electric energy concessionaires. In order to research this topic, this paper utilizes literature review of normative, jurisprudential and scholarly works; therefore, promoting critical-deductive reasoning. From this sense, the need for energy should be seen as a fundamental right, whilst Brazil should also focus on the challenges of environmental protection. Moreover, there should be environmental liability if any energy provision causes environmental harm.

Keywords: Public Service, Hydroelectric energy, Civil Liability. 


\section{INTRODUÇÃO}

O presente artigo consiste na abordagem inicial do conceito de serviço público diante da doutrina de alguns administrativistas. Este conceito é importante para balizar os elementos e critérios da identificação das atividades que caracterizam serviço público.

Nesta linha, constata-se o dever do Estado em prover para o cidadão, prestações sociais passíveis de possibilitar uma vida em sociedade apta a possibilitar um mínimo de dignidade da pessoa humana. Não destoa deste dever, a prestação do serviço público de fornecimento de energia elétrica.

Afinal, no mundo moderno, são várias as atividades que requerem o uso de energia, tornando-a com uma necessidade básica.

Por extensão, as diversas formas de obtenção de energia, por menos poluentes que sejam, ocasionam pontos positivos e negativos, com potenciais impactos ambientais.

A ocorrer tal fato, exsurge também os limites responsabilidade civil das empresas prestadoras de serviço de fornecimento de energia elétrica, na medida em que elas fazem às vezes do Estado na prestação do serviço público.

Efetuando estes importantes registros, a estruturação do trabalho desenvolve-se apresentando os fundamentos da prestação de serviços públicos pelo Estado, e a devida prestação do serviço público do fornecimento de energia elétrica considerada como um direito fundamental. Em seguida, expõem-se os limiares desta responsabilidade do fornecimento de energia ao lume dos limites da responsabilidade civil. Por fim, destaca-se que o exercício eficaz da prestação de um serviço público, no setor energético, deve pugnar pela proteção ambiental.

Nesse sentido, o presente artigo aborda a prestação do serviço público, no âmbito do Estado e do fornecimento de energia, posto diante do cenário da responsabilidade civil e sua inserção na proteção ambiental. Busca-se com este trabalho, sob o prisma da responsabilidade civil, debater sobre a efetividade da prestação do serviço público de fornecimento de energia elétrica, tendo como premissa um direito fundamental.

Para alcançar o objetivo pretendido com a pesquisa, o estudo apoiar-se-á na Constituição Federal, na legislação, na jurisprudência, e revisão de literatura, em interseção ao trinômio serviço público, direito fundamental e responsabilidade civil ambiental. A metodologia a ser utilizada para a realização deste trabalho será o método de abordagem dedutiva, através da exploração do acervo acima citado.

\section{A DEVIDA PRESTAÇÃO DO SERVIÇO PÚBLICO E O DIREITO À ENERGIA COMO DIREITO FUNDAMENTAL}

2

As necessidades de uma coletividade são consolidadas pela lei com a definição de um serviço como público, e a partir da regulação é concebido as forma de prestação destes serviços à sociedade. Com efeito, na doutrina, o conceito de serviço público pode ser delineado, tal como 
apresentado alguns administrativistas (GALVÃO, 2016).

De acordo com Hely Lopes Meirelles, "serviço público é todo aquele prestado pela Administração ou por seus delegados, sob normas de controles estatais, para satisfazer necessidades essenciais ou secundárias da coletividade, ou simples conveniências do Estado" (MEIRELLES, 1993, p. 289).

Já consoante ao Professor Celso Antônio Bandeira de Mello, conceitua-se serviço público de maneira sintetizada, como:

Toda atividade de oferecimento de utilidade ou comodidade material destinada a satisfação da coletividade em geral, mas fruível singularmente pelos administrados, que o Estado assume como pertinente a seus deveres e presta por si mesmo ou por quem lhe faça as vezes, sob um regime de Direito Publicoportanto consagrador de prerrogativas de supremacia e de restrições especiais-, instituído em favor dos interesses definidos como públicos no sistema normativo (MELLO, 2001, p. 600).

Para Eros Roberto Grau, a Constituição apresenta todos os contornos da noção jurídicobrasileira de serviço público. Assim o faz quando aparta essas atividades daquelas próprias dos particulares, entregando-as ao Estado como sendo um dever-poder (GRAU, 2001, p. 249).

Partindo para a conceituação do serviço público no âmbito da constitucional, a Constituição Federal de 1988 encerra todos os elementos e critérios para perfeita identificação das atividades que caracterizam serviço público. Desta forma, o de serviço público no direito brasileiro tem como base o Sistema Constitucional. Mesmo que alguma atividade tenha previsão expressa como sendo serviço público, sua natureza jurídica será verificada no texto constitucional e avaliada com a mesma para que se averigue se há ou não de fato a presença de um serviço público (CATÃO, 2002).

Diante do exposto, a Constituição Federal traz no caput, do art. 175, as formas de prestação de serviço público:

Incumbe ao Poder Público, na forma da lei, diretamente ou sob regime de concessão ou permissão, sempre através de licitação, a prestação de serviços públicos.

Parágrafo único. A lei disporá sobre:

I - o regime das empresas concessionárias e permissionárias de serviços públicos, o caráter especial de seu contrato e de sua prorrogação, bem como as condições de caducidade, fiscalização e rescisão da concessão ou permissão;

II - os direitos dos usuários;

III - política tarifária;

IV - a obrigação de manter serviço adequado. (BRASIL, 1988)

Extrai-se da norma, que o Estado brasileiro assumiu o compromisso de garantir para o cidadão, todo um arcabouço de prestações sociais, de forma a viabilizar uma vida em sociedade 
em consonância com a ideia de dignidade da pessoa humana (FRANÇA, 2004, p. 345).

Da mesma forma, verifica-se que a Constituição de 1988 prevê as bases para a uma descentralização da gestão dos serviços públicos, mediante técnicas como a de outorga de concessões e permissões.

No que tange ao tema ora abordado, dispõe o art.22, XII, “b”, da Carta, que:

Compete à União:

$[\ldots]$

XII. explorar, diretamente ou mediante autorização concessão ou permissão:

$[\ldots]$

b) os serviços e instalações de energia elétrica e o aproveitamento energético dos cursos de água, em articulação com os Estados onde se situam os potenciais hidro energéticos (BRASIL, 1988).

Mais adiante, prescreve o art. 175 que "Incumbe ao Poder Público, na forma da lei, diretamente ou sob o regime de concessão ou permissão, sempre através de licitação, a prestação de serviços públicos" (BRASIL, 1988).

E na forma do Parágrafo único desse mesmo dispositivo, ficou estabelecido que a lei deveria dispor sobre:

I - o regime das empresas concessionárias e permissionárias de serviços públicos, o caráter especial de seu contrato e de sua prorrogação, bem como as condições de caducidade, fiscalização e rescisão da concessão ou permissão;

II - os direitos dos usuários;

III - política tarifária;

IV - a obrigação de manter serviço adequado (BRASIL, 1988).

Forçoso é perceber as inúmeras necessidades básicas que permeiam a vida do homem contemporâneo. Tais utilidades básicas extrapolam a necessidade de acesso à alimentação, saúde ou educação, pois afinal, a própria manutenção da saúde, alimentação, bem como o exercício do direito à educação, que são consagrados direitos fundamentais e assegurados pelo art. $5^{\circ}$ da Constituição Federal brasileira. Tais direitos dependem, atualmente, do acesso a outros bens, que mutatis mutantis devem ser considerados, também, como básicos para a concretização da vida digna. Nesta esteira, inclui-se, dentre outros, o acesso à energia elétrica como bem indispensável ao homem (ROSA; PES, 2012, p. 123).

Sob o pálio, há de se pensar os diversos aparelhos eletroeletrônicos que se tornam indispensáveis para uma vida com um mínimo de conforto e que em alguns casos, indispensáveis para o alcance de um mínimo de dignidade, como exemplo, do chuveiro elétrico, que se faz extremamente necessário durante o inverno do sul do Brasil; ainda, das necessárias lâmpadas elétricas nas escolas e casas para os estudantes, e da geladeira para àqueles que precisam guardar seus remédios em temperaturas adequadas (ROSA; PES, 2012, p. 123).

Impende destacar, "no contexto global deve-se perceber que o direito ao mínimo 
existencial não pode ser reducionista, cabendo-lhe garantir apenas um mínimo dos mínimos” (TORRES, 2009), pugna por direitos fundamentais em sentido lato, quer sejam, amplos o suficiente para abarcar todas as necessidades básicas, bem como, assegurar também os meios para que as necessidades básicas sejam satisfeitas.

Com espeque neste raciocínio, podemos definir o direito ao mínimo existencial como:

[...] o núcleo essencial dos direitos fundamentais ancorado nos princípios da dignidade da pessoa humana e do Estado Democrático de Direito e na busca pela felicidade. Após a reserva do mínimo existencial, que garante a igualdade de chances, é que se iniciam a ação da cidadania reivindicatória e o exercício da democracia deliberativa, aptos a assegurar os direitos sociais prestacionais em sua extensão máxima, sob a concessão do legislador e sem o controle contra majoritário do judiciário (TORRES, 2009).

Atinente às considerações, destaca-se que os chamados direitos sociais referem-se à qualidade de vida dos indivíduos e devem ser garantidos pelo Estado. Como concebido na Constituição, em seu artigo $6^{\circ}$, a definição de direitos sociais, objetos de regulamentação por outras normas. Nesta gama de direitos está contemplada a educação, saúde, trabalho, alimentação, transporte, moradia, lazer, Previdência Social, segurança, proteção à maternidade e à infância e a assistência aos desamparados.

Devem-se trazer ao lume, as iniciativas de categorização do acesso à energia elétrica como direito social na Constituição. É o que prevê a Proposta de Emenda à Constituição (PEC) 44/2017 que começou a tramitar no Senado. Tal proposta tem como objetivo elevar o status da necessidade de energia elétrica para garantir o seu fornecimento para todo o território brasileiro. A PEC é justificada com fulcro no argumento de que "o acesso à energia elétrica é de fundamental importância para "garantir a dignidade humana", pois possibilita o uso e acesso de diversos bens e serviços que dependem de fontes elétricas" (BRASIL, 2010).

Sublinhe-se a jurisprudência mais abalizada sobre a matéria, o Superior Tribunal de Justiça (STJ), ao enfrentar situação que envolvia como Agravante a Companhia Energética do Ceará (COELCE) e como Agravado o Município de Jucás, decidiu o STJ no sentido de que não é possível o corte no fornecimento do serviço sem prévia análise da essencialidade do serviço, quando o devedor for ente público (BRASIL, 2010). Da mesma forma, prevalece o entendimento de que, quando o devedor da conta de energia for ente público, não poderá ser realizado o corte de energia indiscriminadamente em nome da preservação do próprio interesse coletivo, sob pena de atingir a prestação de serviços públicos essenciais, tais como hospitais, centros de saúde, creches, escolas e iluminação pública (BRASIL, 2011).

À vista do exposto, a Constituição Federal conceitua e define os serviços públicos, bem como defende a primazia dos direitos fundamentais e do pleno exercício da cidadania, igualmente, é instrumento na defesa da dignidade da pessoa humana em seus aspectos amplos. Por conseguinte, com as atuais demandas, do cidadão, exsurge o direito ao acesso à energia elétrica como um direito 
básico e indispensável.

\section{A DEVIdA PRESTAÇÃO dO SERVIÇO PÚBLICO DE FORNECIMENTO DE ENERGIA E A RESPONSABILIDADE CIVIL}

Destaca-se que para o exercício pleno da dignidade é preciso ter condições basilares para isso, pois, por si só todos tem esse direito, simplesmente por ser pessoa, contudo, exercê-lo exige o preenchimento de uma série de aspectos. Aspectos estes que permeiam garantias mínimas de direito, afinal, a dignidade da pessoa humana abrangem os direitos sociais, e não há como falar em dignidade se não estiver garantido o mínimo vital (NUNES, 2009, p. 25).

Nessa vereda, tratando dos direitos inerentes à prestação de serviços públicos sob o foco da disponibilidade de energia e responsabilidade civil, o caput, do art. 25, da Lei $n^{\circ}$ 8.987/95 (BRASIL, 1995), aduz que o concessionário do serviço público responde objetivamente (independentemente da comprovação de dolo ou culpa) por todos os prejuízos causados ao poder concedente, aos usuários ou a terceiros. Assevera ainda o dispositivo legal que a fiscalização exercida pelo órgão competente não exclui, nem atenua a responsabilidade do concessionário (BOLZAN, 2012).

Enumera-se ainda como responsabilidade, a exigência de prestação de serviço público adequado e eficaz consoante previsão no art. $6^{\circ}$ do Código de Defesa do Consumidor. "Nos termos do art. $6^{\circ}$, da Lei de concessões e permissão, serviço público adequado é aquele prestado com regularidade, continuidade, eficiência, segurança, atualidade, generalidade, cortesia e modicidade tarifária” (FADEL, 2009, p. 38).

Ainda, quanto às concessionárias, que são as prestadoras do fornecimento de energia elétrica, essas aderem também às normas do Código de Defesa do Consumidor. Segundo o art. 140 da resolução 440/2010 da ANEEL:

Art. 140. A distribuidora é responsável, além das obrigações que precedem o início do fornecimento, pela prestação de serviço adequado a todos os seus consumidores, assim como pelas informações necessárias à defesa de interesses individuais, coletivos ou difusos.

$\S 1^{\circ}$ Serviço adequado é o que satisfaz as condições de regularidade, continuidade, eficiência, segurança, atualidade, generalidade, cortesia na sua prestação e modicidade das tarifas.

$\S 2^{\circ} \mathrm{A}$ atualidade compreende a modernidade das técnicas, do equipamento e das instalações e a sua conservação, assim como a melhoria e expansão do serviço (ANEEL, 2010).

Tratando-se ainda da responsabilidade, mais especificamente, o Código de Defesa do Consumidor, prevê às concessionárias, em seu artigo 22:

Art. 22. Os órgãos públicos, por si ou suas empresas, concessionárias, permissionárias ou sob qualquer outra forma de empreendimento, são obrigados a fornecer serviços adequados, eficientes, seguros e, quanto aos essenciais, 
contínuos.

Parágrafo único. Nos casos de descumprimento, total ou parcial, das obrigações referidas neste artigo, serão as pessoas jurídicas compelidas a cumpri-las e a reparar os danos causados, na forma prevista neste código (BRASIL, 1990).

Ora face às considerações acima, conclui-se que: "o serviço público só é eficiente se for adequado" (NUNES, 2009, p. 105), respeitando as condições acima apontadas. A eficiência relativa a serviço público é exigida pelo Código de Defesa do Consumidor e sua observação atende a outros princípios que decorrem dele.

Retomando o pensamento de Hely Lopes Meirelles, e a respeito do princípio da eficiência voltado à prestação do serviço público: “é o mais moderno princípio da função administrativa, que já não se contenta em ser desempenhada apenas com legalidade, exigindo resultados positivos para o serviço público" (NUNES, 2009, p. 104). Isso significa dar aos consumidores não apenas a devida prestação do serviço, mas sim garantir o direito de que estes tenham a satisfação de recebêlo sem imperfeições, vícios e transtornos.

É de se perceber que o fornecedor de serviço público tem alguns princípios aos quais deve respeitar e que o fazem ser responsável por danos causados aos consumidores, seja por defeitos atinentes a prestação de serviço, ou pelas informações insuficientes e/ou inadequadas, nos termos do artigo 14, do Código de Defesa do Consumidor (NUNES, 2009, p. 104).

Nesse sentido, vale coaduna o entendimento de Maria Helena Diniz, o qual a responsabilidade civil gera a obrigação de indenizar, em suas palavras: "a responsabilidade civil tem, essencialmente, uma função reparadora ou indenizatória. Indenizar é ressarcir o dano causado, cobrindo todo o prejuízo experimentado pelo lesado" (DINIZ, 2005, p. 131), significa dizer que apontar a responsabilidade civil em determinada situação é identificar quem responderá pela reparação do dano que resultar dessa, isso porque se houve lesão nasce a encargo de indenizar.

Conforme Guimarães (2006, p. 233) indenização por danos materiais acontece "quando afeta fisicamente a pessoa, seus bens corpóreos ou interesses econômicos." Rizzato Nunes (2009, p. 177) entende que é composta pelos danos emergentes e os lucros cessantes, Guimarães (2006, p. 234) por sua vez, diz que "é o efeito, direto e imediato, de ato ilícito, prejuízo que alguém sofre por deterioração, diminuição atual do patrimônio ou pelo que razoavelmente deixou de ganhar. Enseja reparação de perdas e danos".

Corroborando o entendimento dos princípios ora expostos e requisitados pelos serviços públicos prestados pelas concessionárias de serviços públicos no setor de energia e sob o âmbito da responsabilidade civil, o Supremo Tribunal Federal (STF), em um agravo de instrumento no recurso extraordinário assim decidiu:

AGRAVO EM RECURSO EXTRAORDINÁRIO. DANOS MATERIAIS. FALHANA PRESTAÇÃO DE SERVIÇO. IMPOSSIBILIDADE DE REEXAME DE PROVAS. SÚMULA N. 279 DO SUPREMO TRIBUNAL FEDERAL. AGRAVO AO QUAL SE NEGA SEGUIMENTO. [...] "APELAÇÃO CÍVEL. RESPONSABILIDADE CIVIL. AÇÃO DE RESSARCIMENTO DE DANOS 
MATERIAIS. QUEDA DE ENERGIA ELÉTRICA. DANOS EM APARELHO DE EMPRESA SEGURADA. PAGAMENTO DE INDENIZAÇÃO. SUBROGAÇÃODASEGURADORA. FALHANAPRESTAÇÃO DE SERVIÇOPOR PARTE DA CONCESSIONÁRIA. CASO FORTUITO NÃO DEMONSTRADO. DEVER DE INDENIZAR. MANUTENÇÃO DA SENTENÇA. PRECEDENTES DESTA CORTE. APELO DESPROVIDO”. 2. A Agravante afirma ter o Tribunal de origem contrariado o art. $37, \S 6^{\circ}$, da Constituição da República. Argumenta que, "independentemente da responsabilidade objetiva que possa recair sobre a recorrente por conta da concessão de serviços públicos, esta resta afastada quando não comprovado o nexo causal entre a conduta da concessionária e os danos sofridos pela parte recorrida". [...]. "Demonstrado o dano e sendo" ao ofensor (omitente) imputado a conduta lesiva que resultou na queda ou ausência de energia elétrica, cabia à empresa ré demonstrar que o defeito não pode lhe ser exigido, o que não ocorreu, ante a não juntada aos autos de prova nesse sentido. No caso em tela, não se verifica a ocorrência de nenhuma causa de exclusão de responsabilidade, portanto, configurado está o dever de indenizar, haja vista que estão presentes os três elementos da responsabilidade civil, quais sejam: o dano, a conduta ilícita civil e o nexo causal entre esta e àquela. Logo, decorre o dever de indenizar. [...].STF - ARE: 830518 RS, Relator: Min. CÁRMEN LÚCIA, Data de Julgamento: 25/08/2014, Data de Publicação: Dje-167 DIVULG 28/08/2014 PUBLIC 29/08/2014. (BRASIL, 2014).

Do exposto, forçoso é concluir tratando-se da prestação do serviço de distribuição de energia elétrica, as concessionárias devem ser responsabilizadas objetivamente por todos os prejuízos causados aos consumidores, independentemente de culpa conforme já explicitados acima.

\section{A DEVIDA PRESTAÇÃo do SERVIÇO PÚBLICO DE FORNECIMENTO DE ENERGIA E A PROTEÇÃO AMBIENTAL}

Cumpre apontar que cada forma de obtenção de energia, seja de forma renovável ou não, possui pontos positivos e negativos, todavia os pesos para cada forma devem ser atribuídos corretamente para que o planejamento seja válido e realmente possa mitigar os impactos ambientais. Urge o conhecimento e a quantificação adequada bem como um amplo planejamento energético como forma de mitigar os impactos ambientais provocados pela obtenção de energia elétrica (INATOMI; UDAETA, 2005, p. 189).

E a obtenção de energia sempre gera algum tipo de impacto ambiental, e conforme o empreendimento seja em grande ou pequena proporção. É com um planejamento integrado de recursos bem desenvolvido e devidamente avaliado, que é possível analisar a real necessidade de implantação de um projeto, mitigar os impactos ambientais provenientes da obtenção de energia elétrica, e promover o desenvolvimento sustentável (INATOMI; UDAETA, 2005, p. 189).

Face às considerações aduzidas, o Direito Ambiental impõe as regras e ações de proteção ambiental, nesta esteira, Pozzetti e Moneverde (2013, p. 203) ensinam que: 
Os objetivos do Direito Ambiental é estabelecer regras cogentes, de maneira a prevenir danos futuros. Neste sentido, o direito ambiental atua no campo educativo, preventivo e não no âmbito reparador. As regras são postas no sentido de que as ações sejam tomadas antes que o dano se consolide. Como a crise ambiental assola o planeta como um todo, gerando diversas catástrofes, o direito ambiental se consolida através dos Princípios que lhe são próprios, no sentido de se invocá-los diante da ameaça de danos à saúde pública e ao meio ambiente. (POZZETTI; MONTEVERDE, 2013, p. 200).

Sob o viés da proteção ambiental, a Carta Constitucional de 1988 consagra, no $\S 3^{\circ}$ do artigo 225, o direito a um meio ambiente sadio, determinando a responsabilização dos infratores em reparar os danos causados. E a Lei n. ${ }^{\circ}$ 9.605/98 (Lei dos Crimes Ambientais), além da visão sistêmica de meio ambiente natural, alarga o conceito e protege expressamente o meio ambiente artificial e cultural, ao arrolar os crimes contra o ordenamento urbano e o patrimônio cultural (BRASIL, 1998).

Uma vez constatada e comprovada a lesão ambiental, torna-se indispensável o estabelecimento da relação de causa e efeito entre o comportamento do agente e o dano dele advindo. Para isto, não é imprescindível que seja somente evidenciada a prática de um ato ilícito, mas que seja efetivamente demonstrada a existência do dano para o qual exercício de uma atividade perigosa exerceu decisiva influência (DALLA ROSA, 2011, p. 163).

Vale ressaltar que, mesmo sendo lícita a conduta do agente, tal fator torna-se irrelevante se dessa atividade resultar algum dano ao meio ambiente. Trata-se de uma consequência advinda da teoria do risco da atividade ou da empresa, o qual cabe o dever de indenizar àquele que exerce atividade considerada perigosa, consubstanciando ônus de sua atividade o dever de reparar os danos por ela causados. Assim, tal teoria decorre da responsabilidade objetiva, adotada pela Lei de Política Nacional do Meio Ambiente.

O dano pode ser denominado como o prejuízo (uma alteração negativa da situação jurídica, material ou moral) causado a alguém por um terceiro que se vê obrigado ao ressarcimento. A doutrina civilista tem entendido que somente é ressarcível o dano que preencha aos requisitos da certeza, atualidade e subsistência (GIEHL, 2006).

Sendo a responsabilidade civil ambiental objetiva, a produção de energia estará obrigada a reparar tanto os danos ocorridos quando ela atua sem a devida licença ambiental ou contrariando as normas por ela impostas, quanto os danos ocorridos quando ela age em estrito cumprimento às normas impostas pela licença ambiental. Do ponto de vista da responsabilização das empresas geradoras de energia, será irrelevante analisar a licitude ou não da atividade, pois isto teria apenas o condão de afastar a culpabilidade do agente o que é totalmente desnecessário para a teoria da responsabilidade objetiva (GIEHL, 2006).

Ainda conforme ensina Giehl (2006), a teoria da responsabilidade civil do Estado adotada pelo Brasil, consoante o que preconiza a maior parte da doutrina nacional, é a teoria do risco administrativo, segundo a qual o Estado responde objetivamente (sem análise da culpabilidade) 
pelos danos que sua atividade cause a terceiros, exigindo-se, apenas, a conduta do agente (positiva ou negativa), o dano e o nexo de causalidade. Vale ressaltar que aos órgãos e entidades ambientais cabe estabelecer padrões e princípios gerais; realizar o Estudo de Impacto Ambiental, o processo de licenciamento ambiental e emitir a respectiva licença ambiental e realizar o controle e a inspeção das atividades das empresas geradoras de energia elétrica.

A guisa da responsabilidade civil, a Constituição Federal prevê, em seu $\S 6^{\circ}$, artigo 37, a responsabilidade das pessoas jurídicas de direito público e de direito privado prestadoras de serviços públicos frente aos danos que seus agentes causarem a terceiros (BRASIL, 1988). Ressaltam-se ainda, no plano legal e regulatório, que a responsabilidade estatal se estende às entidades da administração indireta, como as empresas públicas, as sociedades de economia mista e as autarquias.

Conforme leciona, Santos (2017, p. 40):

A obrigação do Poder Público e da coletividade de efetivação do Estado Socioambiental de Direito, que surgiu com a Constituição de 1988, conduz à reflexão acerca da legalidade dos atos normativos tendentes à relativização da regulação ambiental. É importante mencionar que, por meio do Poder Judiciário, tem se buscado a máxima efetividade dos postulados constitucionais mediante o modelo axiológico denominado 'neoconstitucionalismo', o que pode resultar em conflitos jurídicos e arguições de inconstitucionalidade formal desses atos.

A obrigação de reparar danos, decorrente da responsabilidade civil, é recorrente no judiciário e surge nas mais diversas situações, tais como atropelamentos em rodovias cedidas, acidentes na rede de transmissão elétrica e até mesmo a falta de peixes em um rio em razão da construção de usinas hidrelétricas (BRASIL, 2017).

Assim, as empresas que firmam contratos para a execução de serviços como fornecimento de água ou energia, ou construção e conservação de rodovias, são responsabilizadas pelos possíveis danos na mesma proporção do poder público executando os mesmos serviços. Para o STJ, é aplicada a teoria de risco administrativo do negócio (BRASIL, 2017).

Tal entendimento, pode ser constatado no julgado REsp. 1.330.027:

Quanto à ré, concessionária de serviço público, é de se aplicar, em um primeiro momento, as regras da responsabilidade objetiva da pessoa prestadora de serviços públicos, independentemente da demonstração da ocorrência de culpa. Isso porque a recorrida está inserta na Teoria do Risco, pela qual se reconhece a obrigação daquele que causar danos a outrem, em razão dos perigos inerentes a sua atividade ou profissão, de reparar o prejuízo (BRASIL, 2017).

Sobre a matéria, outro julgado que merece nota é o REsp 1.095.575, a ministra Nancy Andrighi lembrou que, mesmo antes da introdução do Código Civil de 2002, já era reconhecida a responsabilidade objetiva da concessionária de serviços públicos, tendo em vista o risco inerente à atividade exercida (BRASIL, 2017). 
Outro caso digno de nota e que demonstra os limites da responsabilidade civil envolvendo a prestação de serviço de geração de energia, sobrevém o caso envolvendo a instalação das Usinas Hidrelétricas Canoas I (entre Cândido Mota/SP e Itambaracá/PR) e II (entre Palmital/SP e Andira/ PR), de propriedade da concessionária Duke Energy. O Inf. 574 do STJ sintetiza o julgamento:

O pescador profissional artesanal que exerça a sua atividade em rio que sofreu alteração da fauna aquática após a regular instalação de hidrelétrica (ato lícito) tem direito de ser indenizado, pela concessionária de serviço público responsável, em razão dos prejuízos materiais decorrentes da diminuição ou desaparecimento de peixes de espécies comercialmente lucrativas paralelamente ao surgimento de outros de espécies de menor valor de mercado, circunstância a impor a captura de maior volume de pescado para a manutenção de sua renda próxima à auferida antes da modificação da ictiofauna (BRASIL, 2017).

Em resumo, para a instalação das usinas, foi necessário o represamento do rio, de modo que as condições ambientais ficaram mais propícias a espécies de peixes de médio/pequeno porte (ditas "sedentárias", em contrapartida às "migradoras", muitas vezes de grande porte). E desta forma, seguiram-se rigorosamente as exigências legais, tendo havido EIA/RIMA que apontou, dentre as condicionantes, a necessidade de introdução de espécies de peixes mais adaptadas à vida no lago (represa) das hidrelétricas.

Inconformado com a instalação das usinas e o represamento do rio, um pescador profissional artesanal, que exercia sua profissão nesse rio, pediu indenização por danos materiais e morais, sustentando ter havido diminuição/desaparecimento de peixes de espécies comercialmente lucrativas, paralelamente ao surgimento de outros de espécies de menor valor de mercado. Tendo a sentença acolhido os seus pedidos, fixando, a título de danos materiais, pensionamento de $1 / 2$ salário mínimo mensal até a data da aposentadoria do autor e R $\$ 7.000$ a guisa de danos morais. Interposta apelação, o TJ/PR manteve a sentença objurgada. Daí o recurso especial ao STJ. (EMAGIS, 2018).

À vista do exposto, a responsabilidade da empresa prestadora do serviço perseguem os mesmos critérios da responsabilidade do Estado; uma vez que o comando constitucional alcança a empresa de Direito Privado que prestar serviço público. Nesta toada, significa que o concessionário vai responder pelos danos causados ao usuário. Havendo nexo causal entre o dano e a conduta, a empresa será responsável. Oportuno ressaltar que o comando do artigo em comento protege tanto o usuário do serviço quanto o terceiro que sofra o dano (RIBEIRO, 2014, p. 16).

O deslinde da questão, é que se constata evidente que as concessionárias respondem pelos prejuízos sejam eles causados aos usuários do serviço ou a terceiros. Bruno Gonçalves Pereira em passagem clara assim esclarece:

[...] na hipótese da concessionária de energia elétrica, em plena atividade de reparação de cabos elétricos, ou seja, no exercício da prestação do serviço objeto da concessão, venha a provocar dano a terceiros, devera responder de forma objetiva, conforme se extrai do já citado artigo $37, \S 6^{\circ}$, Carta Magna. A 
entidade sujeitar-se-á a responsabilidade objetiva como se fora o próprio Estado. (PEREIRA, 2013, p. 62).

Conclui-se que as concessionárias de serviços públicos respondem pelos danos e prejuízos causados, na medida em que elas fazem às vezes do Estado na prestação do serviço público.

\section{CONSIDERAÇÕES FINAIS}

Extraem-se da análise doutrinária o reconhecimento que o serviço público de fornecimento de energia é necessário à vida contemporânea e a plena satisfação dos anseios sociais, inclusive como meio de prover uma vida em sociedade em consonância com a ideia de dignidade da pessoa humana.

Em que pese as várias necessidades diárias e essenciais do cidadão, a exemplo da educação e da saúde, sustenta-se que o direito à energia elétrica, atualmente, possui uma valoração jurídica, social e antropológica, alçada ao rol dos direitos fundamentais.

Ao final desse trabalho verificou-se que apesar do acesso à energia elétrica ser considerado um direito fundamental e, portanto, intimamente ligado à dignidade da vida humana, muitas vezes, a sua indispensabilidade não é reconhecida pelo Estado, acarretando, por vezes, uma infeliz judicialização daquilo que deveria ser uma política pública promovida espontaneamente pela Administração.

À luz do panorama apresentado, é necessário reconhecer que ter acesso à energia elétrica propicia que os indivíduos tenham melhores condições de vida e, por vezes, à própria vida, como nos casos de equipamentos hospitalares que permitem a manutenção da atividade cardíaca ou respiratória.

Lado outro, colocar em disponibilidade energia elétrica em suas várias fontes, exige o estudo da responsabilidade jurídica, eminentemente, a civil e ambiental.

Assim, as concessionárias que tem por escopo a produção de energia estão obrigadas a reparar tanto os danos ocorridos quando atuam sem a devida licença ambiental ou contrariando as normas por ela impostas, bem como, quando os danos ambientais ocorreram apesar do cumprimento às normas impostas pela licença ambiental.

Incide sobre a prestação de serviços de fornecimento de energia elétrica e suas nuances de produção, o fator de proteção ambiental. Fator este sempre sustentado na responsabilidade civil ambiental objetiva. Desta forma, enfatizou-se no trabalho que a responsabilização das empresas geradoras de energia independe da licitude ou não da atividade, bem como, dos elementos subjetivos do dolo ou culpa, ante a adoção da teoria da responsabilidade objetiva.

Conclui-se, portanto, que o tema em questão se reveste de robusta complexidade, porquanto, na medida em que o direito ao acesso à energia é fundamental, importante também é a construção de uma doutrina jurídica vigorosa que fundamente a responsabilidade das empresas fornecedoras de energia, sempre em vista à construção de uma sociedade fundada na Dignidade 
da Pessoa Humana que exige o acesso à energia e que a vida se insira, sem paradoxo, em um meio ambiente ecologicamente equilibrado.

\section{REFEFERÊNCIAS}

ANEEL - AGÊNCIA NACIONAL DE ENERGIA ELÉTRICA. Resolução Normativa no 414, de 9 de setembro de 2010. Estabelece as Condições Gerais de Fornecimento de Energia Elétrica de forma atualizada e consolidada. 2010. Brasília, DF: ANEEL, 2010. Disponível em: http:// www2.aneel.gov.br/cedoc/ren2010414.pdf. Acesso em: 30 abr. 2018.

BOLZAN, Fabrício. Serviços públicos. Jus Brasil. 2012. Disponível em: https://fabriciobolzan. jusbrasil.com.br/artigos/121819347/servicos-publicos. Acesso em: 2 abr. 2018.

BRASIL. [Constituição (1988)]. Constituição da República Federativa do Brasil de 1988. Brasília, DF: Presidência da República, 1988. Disponível em: http://www.planalto.gov.br/ ccivil_03/constituicao/constituicao.htm. Acesso em: 27 nov. 2019.

BRASIL. Lei $\mathbf{n}^{\mathbf{0}} \mathbf{8 . 0 7 8}$, de 11 de setembro de 1990. Dispõe sobre a proteção do consumidor e dá outras providências. Brasília, DF: Presidência da República, 1990. Disponível em: http://www. planalto.gov.br/ccivil_03/Leis/L8078.htm. Acesso em: 30 abr. 2018.

BRASIL. Lei $\mathbf{n}^{\mathbf{0}}$ 8.987, de 13 de fevereiro de 1995. Dispõe sobre o regime de concessão e permissão da prestação de serviços públicos previsto no art. 175 da Constituição Federal, e dá outras providências. Brasília, DF: Presidência da República, 1995. Disponível em: http://www. planalto.gov.br/ccivil_03/leis/18987compilada.htm. Acesso em: 5 out. 2019.

BRASIL. Lei no 9.605, de 12 de fevereiro de 1998. Dispõe sobre as sanções penais e administrativas derivadas de condutas e atividades lesivas ao meio ambiente, e dá outras providências. Brasília, DF: Presidência da República, 1998. Disponível em: http://www.planalto. gov.br/ccivil_03/leis/19605.htm. Acesso em: 9 out. 2019.

BRASIL. Superior Tribunal de Justiça. A responsabilidade do Estado e das concessionárias de serviços públicos. Especial Notícias STJ, Brasília, 2017. Disponível em: http://www.stj. jus.br/sites/STJ/default/pt_BR/Comunica $\% \mathrm{C3} \% \mathrm{~A} 7 \% \mathrm{C3} \% \mathrm{~A} 3 \mathrm{o} /$ noticias/Not $\% \mathrm{C} 3 \% \mathrm{ADcias} /$ A-responsabilidade-do-Estado-e-das-concession $\% \mathrm{C} 3 \% \mathrm{~A} 1$ rias-de-servi $\% \mathrm{C} 3 \% \mathrm{~A} 7 \mathrm{os}-$ p\%C3\%BAblicos. Acesso em: 30 abr. 2018.

BRASIL. Superior Tribunal de Justiça. Agravo Regimental n 1.329.795 - CE (2010/01318519). Agravante: Companhia Energética do Ceará - COELCE. Agravado: Município de Jucás. Relator: Ministro Herman Benjamin, 5 de outubro de 2010. Disponível em: https://stj.jusbrasil. com.br/jurisprudencia/15995702/ag-1329795. Acesso em: 17 maio 2014.

BRASIL. Superior Tribunal de Justiça. Agravo Regimental no 1.336 .503 - RO (2010/01444082). Agravante: Centrais Elétricas de Rondônia S/A - CERON. Agravado: Porto do Velho Comércio de Alimentos Ltda. Relator: Ministro Cesar Astor Rocha, 5 de fevereiro de 2011. Disponível em: https://stj.jusbrasil.com.br/jurisprudencia/17133542/ag-1336503. Acesso em: 2 maio 2018.

BRASIL. Supremo Tribunal Federal. Agravo Regimental ARE: 830518 RS. Relator: Min. 
Cármen Lúcia, 25 de agosto de 2014. Disponível em: http://www.stf.jus.br/portal/jurisprudencia/ visualizarEmenta.asp?s1=000218082\&base=baseMonocraticas. Acesso em: 30 abr. 2018.

CATÃO, Adrualdo de Lima. O serviço público no direito brasileiro. Breves comentários acerca de sua natureza jurídica. Revista Jus Navigandi, Teresina, ano 7, n. 54, fev. 2002. Disponível em: https://jus.com.br/artigos/2606. Acesso em: 25 abr. 2018.

DALLA ROSA, Mardióli. O dano ambiental ocasionado pela exploração desenfreada dos recursos naturais. Veredas do Direito: direito ambiental e desenvolvimento sustentável, Belo Horizonte, v. 7, n. 13-14, 2011. Disponível em: https://www.domhelder.edu. br $\% 2$ Frevista $\% 2$ Findex.php $\% 2$ Fveredas $\% 2$ Farticle $\% 2$ Fdownload $\% 2 F 16 \% 2 F 152 \&$ usg $=\mathrm{AOvVa}$ w1SERX9s4-dA8Y1hY8Uinio. Acesso em: 30 abr. 2018.

DINIZ, Maria Helena. Curso de direito civil brasileiro. 19. ed. São Paulo: Saraiva, 2005. v. 7.

EMAGIS. Danos ocasionados por construção de hidrelétrica. 2018. Disponível em: http:// www.emagis.com.br/area-gratuita/voce-sabia/danos-ocasionados-por-construcao-de-hidreletrica/. Acesso em: 30 abr. 2018.

FADEL, Marcelo Costa. O direito da energia elétrica sob a ótica do consumidor. Rio de Janeiro: Lumen Juris, 2009.

FRANÇA, Vladimir da Rocha. Reflexões sobre a Prestação de Serviços Públicos por Entidades do Terceiro Setor. Revista de Direito Administrativo, Rio de Janeiro, n. 238, p. 345, out./dez. 2004. Disponível em: http://bibliotecadigital.fgv.br/ojs/index.php/rda/article/ viewFile/44086/44759. Acesso em: 30 abr. 2018.

GALVÃO, Vitor Turton Lopes. Breves considerações sobre o conceito de serviço público. Conteúdo Jurídico, Brasília, 16 abr. 2016. Disponível em: http://www.conteudojuridico.com. br/?artigos\&ver $=2.55656 \&$ seo $=1$. Acesso em: 25 abr. 2018.

GIEHL, Germano. A responsabilidade civil ambiental e o gás natural. Portal Jurídico-Trinolex. com, v. 2, n. 1, 2006. Disponível em: http://www.ambitojuridico.com.br/site/index.php/\%3Fn_ link\%3Drevista_artigos_leitura\%26artigo_id\%3D12559\%26revista_caderno\%3D28?n link=revista_artigos_leitura\&artigo_id=4339\&revista_caderno=5\#_ftn17. Acesso em: $29 \mathrm{abr}$. 2018.

GRAU, Eros Roberto. Constituição e serviço público. In: GRAU, Eros Roberto; GUERRA FILHO, Willis Santiago. Direito constitucional: estudos em homenagem a Paulo Bonavides. São Paulo: Malheiros, 2001. p. 249.

GUIMARÃES, Deocleciano Torrieri. Dicionário técnico jurídico. 8. ed. São Paulo: Rideel, 2006.

INATOMI, Thais Aya Hassan; UDAETA, Miguel Edgar Morales. Análise dos impactos ambientais na produção de energia dentro do planejamento integrado de recursos. 2005. Disponível em: https://www.academia.edu/36538516/AN\%C3\%81LISE_DOS_IMPACTOS_ AMBIENTAIS_NA_PRODU\%C3\%87\%C3\%830_DE_ENERGIA_DENTRO_DO_ PLANEJAMENTO_INTEGRADO_DE_RECURSOS 189-205. Acesso em: 5 nov. 2018.

MEIRELLES, Hely Lopes. Direito administrativo brasileiro. São Paulo: Ed. Malheiros, 1993. 
MELLO, Celso Antônio Bandeira. Curso de direito administrativo. 14. ed. São Paulo: Malheiros Editores, 2001.

NUNES, Luiz Antonio Rizzato. Curso de direito do consumidor. 4. ed. São Paulo: Saraiva, 2009

PEREIRA, Rodrigo Gonçalves. Responsabilidade civil das concessionárias de energia elétrica pelos danos causados em decorrência de curto circuito elétrico. Fórum Administrativo. 2013. Disponível em: https://dspace.almg.gov.br/xmlui/handle/11037/5721. Acesso em: 30 abr. 2018.

POZZETTI, Valmir Cesar; MONTEVERDE, Jorge Fernando Sampaio. Gerenciamento ambiental e descarte de lixo hospitalar. Revista Veredas do Direito, Belo Horizonte, v. 14, n. 28, p. 200, jan./abr. 2013.

RIBEIRO, Osmail. Responsabilidade das concessionárias de energia elétrica pelos danos causados aos usuários. 2014. Trabalho de Conclusão de Curso (Graduação em Direito) Faculdade de Direito da Universidade Tuiuti do Paraná, Curitiba, 2014. Disponível em: http:// tcconline.utp.br/media/tcc/2015/05/responsabilidade-das-concessionarias-de-energia-eletricapelos-danos-causados-aos-usuarioS.pdf. Acesso em: 30 abr. 2018.

ROSA, Taís Hemann; PES, João Hélio. Análise jurisprudencial do direito de acesso à energia elétrica. In: CONSELHO NACIONAL DE PESQUISA E PÓS-GRADUAÇÃO EM DIREITO (org.). Direitos sociais e políticas públicas I. São Paulo: Publica Direito, 2012. p. 123-137.

SANTOS, Thiago Flores; POMPEU, Gina Vidal Marcílio. Relativização da regulação ambiental pelo estado de emergência. Veredas do Direito, Belo Horizonte, v. 14, n. 30, p. 117-142, set./ dez. 2017. Disponível em: http://www.domhelder.edu.br/ revista/index.php/veredas/article/ view/1168. Acesso em: 2 abr. 2018.

TORRES, Ricardo Lobo. O direito ao mínimo existencial. Rio de Janeiro: Renovar, 2009.

Como citar: RODRIGUES, Marcos Vinicius; REZENDE, Elcio Nacur. Responsabilidade civil ambiental decorrente do serviço público de fornecimento de energia elétrica. Revista do Direito Público, Londrina, v. 14, n. 3, p. 49-63, dez. 2019. DOI: 10.5433/24157-108104-1.2019v14n3p. 49. ISSN: $1980-511 \mathrm{X}$

Recebido em: 15/05/2018

Aprovado em: 18/02/2019 